\title{
O Transtorno do Espectro do Autista na escola: um labirinto de práticas interligadas na/à alfabetização
}

\author{
Disorder autistic spectrum in current school: a networked practices \\ in literacy labyrinth
}

Ivane Laurete Perotti ${ }^{1}$

\begin{abstract}
Resumo
Este trabalho faz parte de um projeto em execução, que sublinha questões voltadas para o processo de alfabetização em Língua Portuguesa Brasileira, do aluno portador do TEA - Transtorno do Espectro do Autista , em um recorte de escolas públicas e privadas da região metropolitana de Belo Horizonte. Evidencia uma leitura sobre as intervenções pedagógicas a partir do decreto 6.571, de 17 de setembro de 2008 , que determina ao Estado garantir apoio técnico e financeiro para o atendimento especializado em toda a rede pública de ensino. Observa a mediação entre sujeito atípico, ensino sistematizado e instituição escolar. Revisita o papel do professor alfabetizador e indaga sobre as mudanças e os apoios que deveriam acontecer na escola atual para motivar ações insertivas no/do desenvolvimento linguístico do sujeito de perfil autístico. Ainda, o presente trabalho enfatiza a importância de se conhecer as questões comportamentais de uma criança com autismo: como ela reage, como aprende, como funciona a sua memória, o seu modelo de aprendizagem. Entende que, só após uma investigação particularizada, a escola poderá oferecer atividades que se aproximem mais das necessidades e circunstâncias no quadro da atipia.
\end{abstract}

Palavras-chave: Comportamento. Autismo. Multidisciplinaridade. Alfabetização. Intervenções.

\begin{abstract}
Abstact
This work is part of an ongoing project that highlights issues related to the literacy process in the Brazilian Portuguese Language of the student with TEA - Autism Spectrum Disorder - in a cut of public and private schools in the metropolitan area of Belo Horizonte. It shows a reading on pedagogical interventions from Decree 6,571, dated September 17, 2008, which determines the State to guarantee technical and financial support for specialized care in the entire public school system. It observes the mediation between atypical subject, systematized teaching and school institution. It revisits the role of the literacy teacher and inquires about the changes and supports that should happen in the current school to motivate insertive actions in the linguistic development of the subject with an autistic profile. Moreover, the present work emphasizes the importance of knowing how the behaviors of a child with autism: how it reacts, how it learns, how its memory works, or its model of learning. It is understood that, only after an individualized investigation, the school may offer activities that are closer to the needs and circumstances of atypia.
\end{abstract}

Keywords: Behavior. Autism. Multidisciplinarity. Literacy. Interventions.

Artigo recebido em 10 de Novembro de 2016 e aprovado em 20 de Março de 2017.

1 Especialista em Metodologia e Prática da Língua Portuguesa/UNICAMP/SP, mestre em Linguística/UFSC/SC/Análise do Discurso; Filósofa Clínica/INSTITUTO PACKTER/RS, professora, palestrante e terapeuta linguística. E-mail: ivaneperotti@ hotmail.com. 


\section{Introdução}

O foco deste ensaio é uma leitura acerca das práticas funcionais de intervenção aplicadas no trabalho com os portadores de Transtorno do Espectro do Autista em ambiente escolar, refazendo um olhar sobre o processo de alfabetização em Língua Portuguesa Brasileira; aponta ações e estratégias pedagógicas, discute o papel do professor regente, do profissional auxiliar e da família na resolução de problemas comuns ao contexto autístico. Agrega-se à leitura, uma análise da situação atual da escola de inserção e da aplicação do decreto 6.571, de 17 de setembro de 2008, que determina ao Estado garantir apoio técnico e financeiro para o atendimento especializado em toda a rede pública de ensino.

As metodologias aplicadas ao processo de aquisição da linguagem na escola regular é motivo de variadas e diferentes pesquisas na área da educação formal. Trabalhar as etapas que envolvem o domínio de particularidades específicas da língua oral e da língua escrita exigem tarefas tecnicamente distintas. A natureza plural da linguagem e o construto convencionado da língua escrita propõem ao sujeito social que se habilite ao domínio de práticas sociais, nem sempre negociadas no campo da escolarização. À escola cabe a reflexão sobre as línguas que se identificam no manuseio da língua nativa. Falar em Língua Portuguesa Brasileira é falar em variedades dessa mesma língua - nunca uma só, mesmo em se considerando o tempo histórico para as mudanças da estrutura escrita (nem tão longe quanto se pensa, nem tão perto quanto talvez se desejasse) e a rapidez com que se fundam as práticas sociais em novos e criativos gêneros de discurso.

Cabe aqui a distinção preliminar e a demarcação básica - sem qualquer pretensão de encurtar as considerações - entre dois conceitos que se embaralham nas didáticas de aquisição: alfabetização e letramento.

$\mathrm{O}$ ato de alfabetizar não prescinde o sujeitamento social, tanto quanto o letrar não acontece fora de um contexto de vivência e formação discursiva. Ocorre que, por vias de várias mãos, os especialistas vêm postulando - não sem notórias divergências - que, à escola cabe alfabetizar letrando. Ou seja, a presença de habilidades metalinguísticas seria essencial para a aquisição da linguagem em contexto de ensino regular, no qual, conferindo o texto da lei 6.571, inclui-se a criança com desenvolvimento e/ou comportamento atípico. Implicaria dizer que a capacidade de refletir sobre a própria língua determinaria seu processo de aquisição: segmentação da fala, consciência fonológica, percepção sígnica dos construtos alfabéticos. A postulação sublinha um ambiente pré-escolar de vivência linguística em quadros de vários estímulos - mais ou menos naturais, em se pensando que cada contexto familiar envolve uma determinada situação e uma comunidade específica (condições de 
produção social, cultural, econômica, variedades linguísticas e acessibilidade ao entorno contemporâneo). Daí a grande ênfase que os conceitos sobre o letramento têm recebido no momento atual, a partir da afirmação pedagógica de que a alfabetização se dá em uma cadeia de evolução continuada, enquanto o letramento propicia as práticas sociais que envolvem a língua escrita em dado momento histórico de interação.

Para Tfouni (1995, p.20),

Enquanto a alfabetização ocupa-se da aquisição da escrita por um indivíduo, ou grupo de indivíduos, o letramento focaliza os aspectos sócio-históricos da aquisição de um sistema escrito por uma sociedade.

Considerando a natureza da atipia que caracteriza o comportamento da criança com TEA (Transtorno do Espectro do Autista), torna-se importante retomar a questão do ambiente linguístico e as habilidades metalinguísticas apontadas pelos estudos como determinantes no processo de aquisição de linguagem. Dependendo da gravidade do evento neurotípico, o contato com o universo da linguagem muda de indivíduo para indivíduo, em um novo e irregular quadro de características que a escola não tem como prever, mas pode mediar, a partir de intervenções particularizadas, e de comum acordo com a família e os profissionais envolvidos no trato da criança autista. O que pode parecer ideal e improvável em um primeiro momento, exige dos educadores envolvidos um trabalho direcionado para a intervenção na aquisição da linguagem, estabelecendo conceitos e tarefas para o que se tem chamado de habilidades metalinguísticas. Assim, surgem as mediações por movimentos que recriam ou estimulam o contato especial e singular do processo linguístico, outro ponto deste ensaio, ao se pensar que, adquirir linguagem corresponde aqui a fazer-se sujeito de uma ação no mundo significado: uma possibilidade para as crianças do espectro autístico.

\section{Comportamento Humano: eventos e subjetividade}

Em se tratando do comportamento, diz-se das ações que o expressam ou negam em escalas e variáveis que não se caracterizam pelo princípio concreto da observação exterior como fatos percebidos fora de um contexto. A subjetividade humana, por mais que se entenda imaterial, deflagra cadeias de comportamento apreciáveis e imanentes em dado espaço de ação/interação possíveis e cognitivamente conceituados. Segundo Cooper (2007, p. 3), "[...] tudo o que uma pessoa faz, diz, pensa, ou sente [...]" configura um comportamento, uma ação deflagrada no ambiente dos eventos humanos.

A atividade científica de investigação sobre o comportamento pode capacitar o cientista no manejo da diversidade comportamental humana, mas não o coloca apenas como aquele que olha o fato em si; antes, o investigador participa agentivamente na descrição do 
objeto focado, permitindo-lhe modelar as variáveis cientificamente. Quando tal se dá, de acordo com Skinner (1965), as regras que descrevem a observação são provadas e o fato recortado pode servir de base para estudos e comparações futuras - ou passadas, a depender daquele que efetivamente se vale das contingências observadas. Contudo, para Abib (1993), não cabe à ciência o pressuposto da exatidão como ferramenta de descrição, mas sim, pertence ao investigador a possibilidade de corrigi-la.

A sociedade mundial, aproximada pela velocidade do crescimento midiático, promove com agilidade novos tópicos e enfoques comportamentais que se mantêm sob a leitura das análises científicas. Crescem igualmente os escopos das pesquisas na área das Ciências Humanas e o que até pouco tempo atrás não se materializava enquanto objeto de interesse, torna-se premissa para distintas questões e novos olhares. A multidisciplinaridade dos estudos contemporâneos permite a interligação entre as ciências e as suas respectivas redes epistemológicas. Desta forma, o trânsito das informações intercruzam-se e permitem releituras contínuas no campo das intervenções plurais.

O presente trabalho não pretende discutir as várias e competentes escolas de pensamento investigativo que se debruçam sobre os eventos humanos, mas destaca a contribuição da Análise de Comportamento sobre o que tem se intitulado comportamento de autocontrole. Esse estudo é fundamentado, como qualquer outro evento na área, sob o enfoque de condições e variáveis capazes de modificar o ambiente e influenciar o comportamento humano.

Conforme Tourinho (1997), a natureza subjetiva do homem e as considerações acerca de sua potencialização individual, social, interna e externa, alimentam os estudos sobre o ambiente, o contexto, as manifestações de controle e seu oposto: a impulsividade, gerando instrumentos e técnicas de apoio à resolução de problemas enfrentados pela individualização.

Entre os conceitos que referenciam as questões ligadas ao autocontrole, encontramse as ideias sobre evolução e interação social, componente para a transmissão de regras por ensinamento e troca, aprendizagem e apreensão. Quanto mais as regras condicionam os seres humanos a determinadas variáveis de comportamento, mais os próprios indivíduos aprendem sobre o sistema no qual estão mergulhados, o que nem sempre indicará o reconhecimento das regras estabelecidas em um nível de convívio, ou a execução delas em função da troca estabelecida.

A consolidação de regras é devidamente importante para a sobrevivência e evolução da sociedade, a partir do ponto de vista de sua perpetuação; a manutenção das práticas culturais é imprescindível para a sobrevivência do grupo enquanto um todo. Ainda, as regras 
atendem às demandas funcionais quando as consequências naturais são fracas, de baixa magnitude ou operam a logo prazo. (MATOS, 2001).

Considerando que, no sistema atual, os conceitos sobre individuação e produção estão interligados, a pragmática do comportamento autocontrolado responde a leques indiscutíveis de encaixamento, submissão e repetição. Quando um indivíduo retoca o papel social que lhe cabe por herança ou transmissão, a própria cultura recebe o impacto do que é novo e/ou diferente. A tendência, mais ou menos sutil, nas sociedades capitalistas, é manifestar-se pela imposição do controle individual. Nenhum grupo ou instituição poderia exemplificar melhor a questão do que a escola, enquanto ambiente social politicamente multifacetado. É na escola e por ela que se começa este debate.

Recorta-se em Tourinho (2006, p. 03), o conceito que colabora com a alavanca desta proposta, quando o autor argumenta que, por comportamento, tem-se o conjunto de "[...] relações entre ações do homem e eventos do mundo físico e social com o qual ele interage". Na escola, o saber e o fazer têm em comum o mesmo espaço de laboratório social.

\section{TEA - Transtorno do Espectro do Autista: os caminhos para um diagnóstico}

Sem jamais prescindir da avaliação e orientação clínica, a investigação sobre um possível diagnóstico de Transtorno do Espectro do Autista depende da observação sistemática e consistente do comportamento da criança envolvida, em um trabalho conjunto com a família, com as demais crianças que fazem parte do contexto investigado. É comum que no ambiente escolar as situações de ensino sistematizado permitam a observação de algumas atipias, daí caber ao profissional da educação colaborar na investigação e no encaminhamento especializado. Contudo, nem todas as difuldades de aprendizagem dizem respeito às condições neurocognitivas. Muitas defasagens escolares são resultantes de ações pedagógicas ineficientes, o que aponta, outra vez, o papel da escola na educação do sujeito social, tema que exige uma discussão maior.

A busca de informações junto aos pais, à escola, aos professores, aos cuidadores, aos médicos e demais familiares é tarefa imprescindível para investigar o comportamento infantil em quadros que se fazem necessário. É tarefa clínica levantar o histórico infantil desde o nascimento, e não cabe à escola rotular ou tipologizar eventuais atipias de comportamento. $\mathrm{O}$ desenvolvimento pessoal, social, afetivo, a maturidade motora e a evolução do processo de aquisição da linguagem são pontos que podem determinam a análise escolar, mas não a diagnosticam. Alunos com déficit de aprendizagem ou transtornos de comportamento exigem olhares particulares e especializados, mesmo que se tenha clareza sobre as dificuldades da 
escola em empreitadas dessa natureza. As dificuldades não podem impedir o investimento específico na compreensão e conhecimento do sujeito sob a tutela escolar.

Diversificadas estratégias de investigação biológica, comportamental, cognitiva e social fazem parte de progressivas pesquisas desenvolvidas pela neurociência em escopos de ampla transdisciplinariedade. Interessam aos estudos a reunião do maior número de evidências e fatos que permitam analisar o quadro da criança, das condições biológicas ao comportamento, especialmente em momentos de socialização, em circunstâncias de lazer familiar, de atividades escolares, festas e demais interações. Os dados envolvidos no diagnóstico de um sujeito autístico fazem parte direta do contexto em avaliação, pois a análise acontece dentro desse mesmo ambiente e não fora dele. Daí a importância de se ter clatreza quanto ao papel da escola na educação das crianças atípicas e não no apontamento de qualquer patologia: erro disseminado como prática de avaliação.

É importante observar que os próprios pais nem sempre conseguem expressar informações detalhadas em função do envolvimento afetivo, daí ser importante colher dados em vários contextos da vivência da criança, pois ambientes diferentes trazem sinais variados. Cabe ao médico especialista estruturar escalas de avaliações e monitorar questões dirigidas ao entorno da criança, uma vez que o diagnóstico de TEA não se concretiza através de exames precisos, concretos, materiais; antes, é através da junção de dados e de uma análise que passa pela observação subjetiva que se poderá ter um indicador de diagnóstico. Assim, é determinante levar em conta um leque de informações que também envolve o contexto paterno e os familiares em torno deles: a idade dos progenitores no período da concepção, o histórico familiar, ocorrência de déficit de atenção, autismo, síndromes genéticas, transtorno de humor, hiperatividade, entre outros quadros clínicos.

O diagnóstico de TEA tem sido um dos focos em desenvolvimento para especialistas de diversas áreas do comportamento humano: neurocientistas, médicos pediatras, psicólogos, psiquiatras, neurologistas, pesquisadores do comportamento humano, terapeutas ocupacionais, fonoaudiólogos. Um denso caminho de questionamentos não fecha uma conclusão sobre o assunto e já elenca estratégias de apoio ao desenvolvimento pessoal em contexto de interação. Do medicamento prescrito às técnicas de aplicação cognitivas, o disgnóstico precoce do Transtorno do Espectro do Autista desenvolve parâmetros de adaptação e sucessos funcionais, emocionais, sociais e cognitivos em casos já constatados. Dar conta do tratamento multidisciplinar e do apoio escolar ao aluno com TEA tem sido um dos pontos de maior discussão no presente momento da escolarização. Este é o foco no prosseguimento do presente ensaio. 


\section{0 processamento da linguagem em desenvolvimento atípico}

Estudos neurocientíficos têm fornecido conhecimentos importantes sobre a sensibilização auditiva nos portadores de TEA e as condições neurobiológicas que, uma vez investigadas, facilitam escolhas adequadas na intervenção da aprendizagem atípica. Muito se fala no Brasil acerca do fracasso da alfabetização, problema este que atinge igualmente as crianças neurotípicas e, apesar da diversidade dos métodos, nem todos funcionam dentro do esperado em casos típicos ou atípicos. Contudo, as experiências multidisciplinares confirmam que um indivíduo portador de TEA pode ser alfabetizado, dependendo da escolha do método empregado no processo de aprendizagem e levando-se em conta as condições de sua severidade.

É essencial conhecer as questões comportamentais, o desenvolvimento de uma criança com autismo, como ela reage, como aprende, como funciona a sua memória, como se processa o seu modelo de aprendizagem, quais são as suas características para, só depois, oferecer uma intervenção metodológica que se aproxime mais das necessidades e circunstâncias encontradas. E diz-se "mais" tendo em vista o caráter subjetivo, particular e singular de cada caso.

Por experimentos científicos de observação e análise sistemática sabe-se hoje que os portadores de TEA têm audição hiperfocal e considerável facilidade para formatar sons. Temse a impressão - ainda em investigação - que, quanto mais simples for a sequência sonora, mais fácil para o autista materializá-la em um processo no qual a velocidade é unilateral, focal, material. Observa-se que o TEA apresenta uma velocidade um pouco menor de verificar alturas e melodias quando em ambiente sonora de troca ou intercalação, mas, a memória melódica parece ser maior em crianças neurotípicas.

Diante da sistematização da aquisição e desenvolvimento da linguagem verbal, observa-se que a criança autista não é facilmente atraída para a articulação, pois a diferenciação sonora e articular dos sons consonânticos e vocais diferem entre si. Investigações bem calçadas em aparato científico comprovam evidências neurológicas nas quais as respostas neurofisiológicas são significativamente reduzidas no percurso de formação de palavras, diferentemente do que ocorre com indivíduos sem o TEA.

Os sons da fala e os sons musicais são processados de forma diferente e marcadamente importante para os autistas. Pode-se considerar que a música tem um sentido para eles, enquanto ouvem a fala de um modo diferente, com outra significação, com outra motivação. Ou seja, o TEA ouve a linguagem verbal de um modo distinto do modo como ouve uma música. 
A elevada acuidade auditiva faz o autista apresentar uma sensibilidade maior aos sons que pode, em contexto de muitos ruídos, dificultar o processamento do próprio som e até gerar comportamentos de não reforço ao ambiente de interação. O trabalho desenvolvido por musicoterapeutas especializados mostra a necessidade de metodologizar essa convivência diante de vários "barulhos", criando quadros de experiências sonoras diversificadas. Atividades com alteração de tons, volumes e ritmos, têm por objetivo promover primeiramente o que denominam dessensibilização sonora, para só mais tarde desenvolverem a interação com variedades musicais em alturas diferenciadas.

As investigações e pesquisas sistemáticas indicam que, quanto maior a capacidade de fala, maior o suporte no reconhecimento musical e na interação fluída, prazerosa, com os sons melódicos. Para o TEA, o som se transforma em figura: materialização.

\section{Estratégias na aquisição da linguagem verbal em situações escolares de TEA}

\section{1 Metodologia do trabalho}

A presença de uma criança autista tende a alterar o ambiente familiar e não poucas vezes a pressão pelas dificuldades de comunicação e compreensão do comportamento geram rupturas (SILVA, 2012); por mais difícil que seja nominar esses roteiros, tanto a família quanto a escola precisam de apoio e tratamento adequado para manter as relações em um patamar saudável e produtivo. Não se faz menos importante ressaltar que a sociedade ainda sofre as mesmas dificuldades de interação, aceitação e inserção de um TEA, pela contrariedade que emerge de comportamentos alterados e não explicáveis superficialmente. Torna-se mais comum a avaliação social taxar o portador de TEA como sendo uma criança com ausência de disciplina, com problemas de limites claros, ou ainda, de má índole. Essa constatação, além de desumana, infere em aspectos que mantêm pseudoconceitos, rigidez infrutífera, desinformação e um olhar desatento sobre a fase infantil, triste herança dos séculos passados.

O trabalho em discussão condensa os argumentos arrolados:

a) em pesquisa quantitativa de observação direta - por ano escolar (primeiro ano do ensino fundamental I) e pelo número de portadores com transtorno do espectro autista em ensino regular, em três escolas públicas de Minas Gerais e três escolas de ensino privado no mesmo Estado, na faixa etária de 06 a 09 anos de idade (em um total de 03 meninos em escola pública e um menino na escola particular);

b) em pesquisa qualitativa - por leques de aproximação entre os comportamentos dentro e fora da sala de aula, especificamente no que tange ao letramento/alfabetização e 
raciocínio lógico para o prendizado matemático (numeramento, considerando aqui os princípios que marcam a funcionalidade do que se tem chamado de práticas sociais por letramento dentro e fora da escola).

A decisão de não descrever em detalhes individualizados os contextos de inserção das quatro crianças ocorre em função do objetivo deste trabalho, deixando-se para um trabalho específico detalhar as questões pedagógicas de aprendizagem por aluno, por escola e por metodologia aplicada. Assim, em resumo, pode-se dizer que, a partir da observação e análise situacional das duas escolas envolvidas e dos indivíduos inseridos, tanto a prática do letramento quanto a capacitação do professor e/ou do mediador está aquém do que as crianças exigem. Além das escolas particulares estabelecerem um número específico para a matrícula de alunos atípicos (comumente sob o argumento de estrutura inadequada para a inserção de mais de um ou dois alunos por escola), a presença constante de um mediador - a maior parte deles ainda não capacitados - não favorece a intervenção sistematizada de ações mediadoras no letramento inicial. Diferente não se passa na escola pública, quando o estado desloca um mediador para mais de um aluno, em condições de trabalho ainda precário e de baixa qualificação.

O problema da capacitação do mediador é um dos assuntos em alta nas discussões após a lei de inserção escolar, mas com subsídios de qualificação ainda distantes da realidade agreste que permeia a vivência diária daqueles que se propõem a um papel que transita entre o do professor e o aluno atípico, entre o aluno atípico e o professor e as aprendizagens dispostas no planejamento da escola; sem esquecer que dele, mediador, também depende a interação dos demais alunos com o aluno portador de TEA e vice-versa. É uma atividade de presença e atuação constante, quando a linguagem passa por filtros que de longe não se encontram em manuais de alfabetização e condução pedagógica. Dentro do mesmo quadro encontra-se o professor titular que, diante de uma turma dos anos iniciais, lança mão de conhecimentos nem sempre balizados nas faculdades de origem. É quando se observa o papel da intuição, da boa vontade e da flexibilidade do professor que também se faz refém dos currículos engessados. Os programas escolares não são inclusivos e sequer defendem metas de adequação às particularidades dos indivíduos atípicos no aprimoramento de suas condições pessoais e empoderamento de seu papel social. Há de se reconhecer que o assunto tem vindo à tona com maior recorrência, promovendo o questionamento e o pensar sóciopedagógico das crianças com atipia; mas, fecham-se as pesquisas, os seminários, e as revistas especializadas e abre-se a verdadeira lacuna ainda por preencher sobre o fazer escolarizado. $\mathrm{O}$ apoio institucionalizado para trabalhar com crianças do espectro autista depende ainda de 
uma política pública de formação e aplicação. Vale lembrar que o contínuo do espectro lembra uma reta com variações ao longo de seu percurso: a cada caso, uma espeficidade e um grau de comprometimento. Para cada indivíduo, um leque de ações e atividades que podem não ser aplicadas aos demais indivíduos do mesmo perfil e como atender a mais de um aluno autista em uma só classe, com apenas um professor são questões que sugeririam a criação de atividades coordenadas, mais ou menos indicativas dentro de perfis agrupados. Mas, outra vez, a realidade particular do espectro impõe-se contra a tipologização e à criação de manuais didáticos. Assim como qualquer indivíduo considerado típico, o autista aprende ou não em seu próprio tempo e modo. Mas este é um tema para outros trabalhos.

Com base nas observações quantificadas e analisadas, dentre as quatro crianças que frequentam a escola regular desde a educação infantil, nenhuma delas apresenta no momento em que se redige este material, algum nível de letramento compatível com o letramento das outras crianças em estado típico. Considerando a regularidade e aproximação dos estágios entre as quatro crianças, lista-se em resumo os estágios comuns a elas: leitura truncada e/ou não leitura de figuras e associações entre imagens unitárias (conceitos imagéticos não reconhecidos), transposição e repetição de segmentos sonoros básicos ausentes, psicomotricidade ausente ou não motivada para a execução de tarefas de apoio, psicomotricidade fina ausente, leitura de mundo e descrição de quadros circunstanciais narrativas motivadas por circunstâncias reais de sala de aula em contexto imediato ausente, jogos e brincadeiras orientadas distantes da participação instigada (mesmo com a mediação presente), não repetição dos sons básicos, pré-silábicos e não correspondência entre as evoluções de imagem, figuras, desenhos das letras. No decorrer de um ano escolar, as quatro crianças em observação demandaram pouca ou nenhuma interação com as demais crianças, mesmo considerando a facilidade das outras crianças apresentarem-se para a interação. Aos mediadores observados parecia caber mais o trabalho de contenção e regulação do comportamento dos alunos atípicos do que propriamente traduzirem em outras linguagens quais? - a realidade que se avizinhava dentro e fora da sala de aula. Do lado de fora da sala de aula pôde-se observar a maior constância dos movimentos das crianças com TEA (com espaço menor entre os eventos de repetição e ecolalia - comuns e reconhecidos nos perfis observados). Entre os quatro alunos autistas, apenas um deles conseguia permanecer por mais de cinco minutos dentro da sala de aula. Os demais, entre sair e entrar, demoravam-se a buscar algo inalcançável aos olhos de quem quer que os observasse.

Por mais que avancem os estudos em neurociências, a convivência constante com um portador da síndrome exige atitudes para além do conhecimento de diagnóstico, dos 
tratamentos multidisciplinares e do investimento em ações pedagógicas. A exigência transita pelo universo da esperança - subjetiva ou não -, do respeito e paciência humanizada que se impõem aos familiares e cuidadores. A triste ironia é que a realidade pode ter o peso da desistência; e, então, encontramos crianças autistas fora da escola, longe das atividades formais de ensino, isoladas do convívio motivado. Muitas crianças sofrem o abandono da família, de um dos membros da família ou então, permanecem dentro da estrutura familiar em estado de negação: presas e isoladas no mundo que ainda não compreendemos, do outro lado da espessa parede que parece, apenas parece isolar indivíduos típicos e atípicos. A pluralidade das linguagens não se esgota diante do desconhecimento; antes, pode instigar outras possibilidades e investimentos.

Para que se tenha evolução no atendimento, na intervenção, na convivência com sujeitos do espectro, precisa-se desmistificar o momento idealizado pela lei 6.571 e preencher o grande vácuo da intervenção escolar, especificamente na aquisição da linguagem escrita. Mesmo sem garantias, mediar em outras linguagens a linguagem escolarizada, pode ser um começo para o que pensamos estar atrás da parede sensorial das crianças autistas, tendo claro e pronto o quanto o processo da alfabetização letrada exige tempo, insistência e capacitação.

\section{Intervenções: possíveis ações na/pela escola e família}

"Quando as aves conversam com as pedras e as rãs com as águas - é de linguagem que estão falando". (Manoel de Barros)

Falar de linguagem é falar do homem e do homem no mundo, do mundo no homem e de tudo o que o atravessa nessa exaustiva, efêmera e indizível incompletude. Como fazer falar o homem que silencia diante de si mesmo? Possivelmente, nenhuma resposta se aproxime do vão aberto na questão empírica, mas a busca repetida permite aproximar algumas possibilidades.

Pensando no que a escola e a família podem fazer juntas na intervenção, como forma de cooperar com o trabalho especializado de quem atende clinicamente a criança com TEA, este trabalho coloca em discussão atividades simples e básicas que pretendem servir à natureza das investigações sobre casos e métodos. Para cada caso atravessam-se medidas e modos de fazer singulares, passíveis de alteração em seu próprio momento evolutivo que, outra vez, é único e intransferível. Rotular medidas, sistemas e diagnósticos é antecipar as frustrações da não aprendizagem: a criança exige um olhar determinado pelo seu próprio universo, recortado em sequências de observação e retomadas Trabalhar o letramento, sistematizar a alfabetização em crianças atípicas é um investimento que exige capacitação e 
envolvimento. Contudo, em nenhum momento se pensa impossível aprender a aprender, quer se fale em professor, em família, em mediador ou em criança autista. Não é objeto aqui relacionar a atuação dos profissionais especializados no tratamento terapêutico das crianças com TEA, tais como fonoaudiólogos, terapeutas ocupacionais, terapeutas linguísticos, psicólogos, entre outros; mas assinalar que a presença de ações multidisciplinares configura uma possibilidade de mediação.

\subsection{Motivação auditiva}

Descobrir o gosto engendrado na acuidade auditiva de uma criança com TEA normalmente caracteriza tarefa de repetidas tentativas. Contudo, as crianças autísticas terminam por esboçar reações importantes e diferenciadas diante de sons e sons. Tanto na escola quanto na família, os indivíduos envolvidos no cuidado podem direcionar atividades interativas de audição: músicas, instrumentos musicais, batidas ritmadas, batidas em palmas, em copos, em madeira, em utensílios dispostos em casa ou na sala de aula, com o objetivo de oferecê-las uma por vez, mais de uma vez, em sequências alternadas. Diante de um movimento de apreciação, o ato de desfrutar do som junto com a criança, mesmo que talvez ela se mostre inicialmente agitada por percebê-lo, permite um elo de comunicação. Os treinos auditivos com sons diferenciados podem favorecer a percepção e o reconhecimento dos segmentos fônicos que a escola introduzirá em forma de letramento/alfabetização. Não se está a dizer que estas ações já não sejam comuns no ambiente escolar e familiar; o que se propõe é a parceria motivada e a observação metódica de por onde o gosto ou a sensiblidade auditiva da criança traça os seus caminhos. Ainda, em se observando como reage, torna-se importante sistematizar a descontrução e a descontinuidade desse som e de outros mais, abrindo as experiências sonoras à percepção e motivação. O treino ou estímulo auditivo permite compartilhar a vivência, o que não deixa de ser uma forma de comunicação.

\subsection{Motivação visual}

A língua é um construto que desemboca em duas estruturas quase isomórficas: quase, mas não completamente. Falar e escrever exigem duas habilidades que se determinam cada qual em seu ambiente próprio. Assim, aprender a ler e a escrever é diferente de aprender a falar. E, aprender a falar é aprender falares, dentro de uma variedade de formas de dizer. A língua oral não é uma, são várias. Aprendê-las exige mergulho, interação, dialogismo, conversação, presença, prontidão. Exige o reconhecimento da diversidade. Para qualquer criança é um processo de construir e desconstruir para depois juntar o que foi desfeito. Pensar 
essas ações nos anos escolares iniciais de uma criança atípica, certamente nos faz pensar em todo o percurso que a criança deverá fazer para fora de si mesma e para dentro do que a traduz. A escola como um todo, deveria ensinar a ler imagens, antes de ensinar a ler letras, palavras, frases e textos verbais. A imagem é um texto sem letras que infere a língua e estrutura as possíveis transposições que se fazem a partir dela. Essas transposições podem tornar-se ricas, produtivas, abundantes, quase infinitas. Mas para tal, é necessário que a intervenção esteja sendo feita por quem pode motivar o olhar. O olhar pela janela, para fora dela, pela fechadura da porta, para depois dela; o olhar para o mundo próximo, para aquele que se distancia; para a imagem que o papel concentra, que o filme agiliza, que o quadro pinta; para a imagem do cartão da merenda, do ônibus, da cantina; para as propagandas, para os cartoons, para os gibis, para as flores, as folhas, os animais. Não basta que o mundo inteiro esteja aos pés de uma criança autista; faz-se obrigatório que alguém lhe tome pela mão e lhe dirija o olhar insistentemente. Algumas mais rapidamente, outras menos, a depender dessa brecha que nem mesmo a neurociência ainda diz de quanto é. Olhar e ver, para um portador de TEA, exige uma mão que lhe indique e permaneça insistindo na indicação. Dá trabalho? Sim. Como todas as outras crianças o fazem, apenas, talvez, exija maior vontade da parte de quem lhe media o mundo e para o mundo. Assim, todas as imagens, das mais simples e próximas às mais complexas e distantes podem favorecer o contato e a maturação para a aquisição da língua escrita em ambiente de aprendizagem sistematizada. Lembrando sempre que Freire (1988) enfatizou competentemente as naturezas múltiplas das leituras: de mundo, do mundo, das linguagens humanas verbais e não verbais.

\subsection{Motivação conversacional}

Como conversar com quem não lhe dirige o turno da fala? Conversando, simplesmente. Infelizmente, observou-se nas escolas, foco deste trabalho, que o silêncio das crianças em mediação servia como uma folga a quem as acompanhava. Ao professor da sala, parecia oferecer um lenitivo frente aos alunos que exageravam nas solicitações, nas conversas entre colegas e na altura da voz. Enquanto o barulho pedia controle, os meninos autistas fechavam-se na concha do silêncio intransponível. Visível introspecção. E delas provêm as seguintes questões: deve-se respeitar esse silêncio? Por quanto tempo se deixa uma criança com TEA em seu espaço silencioso ou isolado? Deve-se fazer uma intervenção nesses estágios do comportamento autístico? Não será contraproducente chamar à conversa uma criança com TEA que prefere se ausentar e falar pouco ou não falar? São questões pertinentes, mas cabe lembrar que uma das características do evento autístico é o isolamento. 
Então, tanto a escola quanto a família precisa lançar mão do bom senso, da responsabilidade cuidadora, da atenção e do conhecimento da criança para perceber o momento da intervenção e o momento da aceitação do comportamento. Aqui, pensando nas circunstâncias que se determinam pela instigação: momentos de lazer, sala de aula, roda de amigos, reunião familiar, hora das refeições, passeios etc., acredita-se que o ato de provocar e manter a conversação ativa pode inferir em atenção e exercício de linguagem constante. Os sons da fala e a presença daquele que fala reverberam na criança autista como ponto de manutenção de contato humano, social, dialogal, provocando-a, instando-a a fazer parte dos turnos da fala. Conversar exige mais de um sujeito em ação de interlocução. Perceptível ou não, o ato de conversar com a criança autista pode significar para além do que se espera em retorno dialogal imediato.

\subsection{Motivação para o numeramento}

Quantificar o mundo e refendar o código matemático é uma operação de várias mãos. Dentro e fora da escola, os parceiros de uma criança autista podem levá-la a experimentar mais e mais diretamente aquilo que pesa, acumula, subtrai, avoluma, distancia, em movimentos de experiência direta, real, integral. Os números indicam pesos e medidas, mas antes deles, a inferência é experiencial, palpável, perceptível, ou deveria ser. Sabe-se que a alfabetização matemática na escola carece de uma didática voltada para o experimento e observação. No trabalho de peaquisa realizado durante o ano letivo no qual se manteve em foco as quatro crianças autistas já mencionadas, em nenhuma atividade da sala de aula as crianças foram levadas a praticar matemática com e no mundo que as rodeava. A abstração que segue a rotina do ensino dos números deixa um rastro ilógico e improdutivo na vida acadêmica de qualquer criança. E entre aquelas cujas diferenças afastam-nas mais do mundo traduzido?

Independente do espaço, qualquer criança pode ser levada à experimentação concreta para fundamentar o raciocínio lógico. Parece lógico. Mas a prática escolar nega a razão desse processo, na direta inversão do sistema que o impõe. Alfabetizar letras e números é ensinar códigos traduzíveis e desmontáveis, convencionados, mas não estanques. Para além dos números, está a capacidade de chegar até eles e isso é responsabilidade de quem cuida e intervém na aprendizagem evolutiva de uma criança atípica. Frente ao posto, é crucial propor atividades de percepção das medidas imediatas, permitir o manuseio com objetos quantificados, desmontáveis, de encaixe; oferecer formas e espaços mensuráveis, mediar a experimentação de texturas e tamanhos, contar e recontar amostras de variadas espessuras, 
formatos e dimensões. Promover vivências matemáticas conecta as crianças ao mundo e à racionalização do que lhe significa ou virá a significar. A criatividade e a prontidão dos envolvidos no cuidado de um sujeito com TEA pode ser uma variável de sucesso da alfabetização das linguagens matemáticas e das linguagens como um todo.

\subsection{Motivação para a representação/teatratização}

Representamos a nós mesmos em variados papéis sobre palcos que se deslocam sem aviso prévio. Por que não motivar para a representação da vida em cenas recortadas do cotidiano mais básico e simples? A arte do teatro pode ser instalada fora dos palcos convencionais, sem figurinos e alegorias, sem luzes e plateias. Basta ao cuidador, professor, familiar, estabelecer o jogo convidativo de representar o que lhe cerca. Em sala de aula, como atividade planejada, há de se supor que o professor instale um lugar e um momento. Mas, em se pensando naqueles eventos que circundam a convivência do cuidador ou dos familiares, não se faz necessário esperar pela melhor circunstância. $\mathrm{O}$ enfoque pode ser a borboleta ou o bicicleteiro, a mãe batendo um bolo, a irmã menor chorando, o desenho animado da história sobre dragões. Não há limites para a criatividade do envolvimento, do despertar para o simples e o funcional. A pragmática não se engendra na Pedagogia apenas para lhe dar cunho epistemológico: saber fazer e desejar fazê-lo exige determinação, presteza e paciência, quando a criança em questão faz parte do TEA.

A representação é outra atividade que passou longe das escolas observadas durante o ano letivo que motivou parte deste trabalho, salvo uma pequena peça apresentada às crianças de uma das escolas particulares; contudo, não se permitiu que o menino com evento autístico a assistisse por estar demasiadamente agitado (?). É importante ressaltar que há grande diferença entre participar da peça e assistir à peça. Ambas as atividades são importantes, inegavelmente; mas fazer parte de uma representação exige estar nela de vários modos. E são desses modos que falamos aqui. Do simples ato de remedar, imitar, para o ato de representar com maior elaboração; o trabalho explora o diálogo interno, a personificação, a tessitura de um texto revisitado diversas vezes, como se o olhar sobre o outro ou sobre o acontecimento em si se desmantelasse em novas faces, em novos olhares, em novos valores. Motivar para a representação é facilitar a compreensão do outro em si mesmo e encontrar a si mesmo no outro. Tem se observado em oficinas dirigidas às crianças atípicas que essa atividade gera interesse e participação. A família tem um palco armado em cenas de modelos repetíveis, caricaturados, e as representações podem ser diariamente refeitas, feitas e desfeitas. 


\subsection{Motivação pictográfica}

Mover um instrumento sobre uma estrutura que oferece atrito (papel, tela, areia, argila etc.) provoca obrigatoriamente um efeito visual, tátil, sensorial, sinestésico. Pintar em cores acelera a motivação, abre espaço para as expressões pessoais, para as emoções. Pintar sem razão, ao léu, a solto, à deriva, pode ser uma atividade muito bem administrada, desde que o cuidador esteja atento, desde que a família participe, que o professor se deixe tocar pelo que é exposto. Aprende-se desde muito cedo a gerar significados, a promover sentidos, a provocar uma sintaxe de coerência e razão. Não há razões na atipia, apenas a sua natureza subjetiva e singular. Tanto na escola quanto em casa, participar e provocar desenhos livres, riscos, rabiscos, traços no chão, na areia, na argila, no barro fresco que sobra depois da chuva, podem facilitar a promoção do mundo no transtorno que se caracteriza pela isenção e afastamento do mundo imediato. Afirmar que o sujeito com TEA não se comunica é uma imprecisão, pois até onde a neurociência investiga, a tentativa de comunicação parece existir, possivelmente de uma forma que o seu entorno ainda não a compreenda.

\section{Conclusão}

Independente do grau do espectro autista, a criança atípica pode desenvolver-se para estar no mundo que se coloca ao seu redor e lhe exige práticas sociais. Essas práticas amalgamam-se com a formação discursiva, com as habilidades linguísticas em sentido amplo, com as manifestações de fala e de escrita, com a capacidade de expressar conceitos, reconhecer significados. Se cabe à escola o fazer escolarizado, não se tem dúvidas, mas sabemos que a escola que temos neste momento, ainda caminha para uma menor precarização do ensino. Enquanto a evolução se processa, fazer parte da engrenagem que a impulsiona é uma questão de escolha. Muitas crianças autistas são mal atendidas por falta de um diagnóstico adequado; e, nem sempre as crianças diagnosticadas recebem uma intervenção capaz de promover-lhes o crescimento. Infelizmente, ainda não se chegou ao necessário e ao saudável. O chamado mau comportamento infantil configura ferramenta a ser discutida, mas o autismo é um evento psíquico que não pode ser nem mediado, nem medido pela mesma régua escolar. E quando se pensa em motivação para o mundo, pensa-se em todas as manifestações desse mundo em contato com as crianças atípicas de modo mais sistemático, reiterado, assistido e insistido. Não basta fazer um passeio, é preciso fazê-lo participando e explorando o ambiente que se oferece à vista e ao deleite. E talvez o conceito seja esse: deleitar-se significa ter acesso a sensações e sentimentos aprazíveis, uma experiência que parece falhar nos portadores de TEA até que se mostre, com certa teimosia planejada, que a 
experiência agregará sensações que valem ser conhecidas. Escolas capacitadas e currículos articuladamente abertos para a inclusão podem fazer diferença na educação de sujeitos em estado de atipia. 


\section{REFERÊNCIAS}

ABIB, J. A. D. A psicologia é ciência?. Revista Psicologia: Teoria e Pesquisa, Brasília, v.9, n. 3, 1993.

BARROS, Manoel de. Poesia Completa. Rio de Janeiro: Editora Leya, 2013.

COOPER, J. O. et al. Applied Behavior Analysis. 2nd. Columbus: Pearson, 2007.

FREIRE, Paulo. A importância do ato de ler. São Paulo: Cortez, 1988.

MATOS, M. A. Comportamento governado por regras. Revista Brasileira de Terapia Comportamental e Cognitiva, São Paulo, v.3, n.2, 2001.

SILVA, A. B. et al. Mundo Singular. Entenda o Autismo. Rio de Janeiro: Editora Fontana, 2012.

SKINNER, B. F. Science and human behavior. New York: Free Press, 1965.

TFOUNI, L.V. Letramento e alfabetização. São Paulo: Cortez, 1995.

TOURINHO, E. Z. Privacidade, comportamento e o conceito de ambiente interno. In: BANACO, R. A. (Org.). Sobre comportamento e cognição. São Paulo: Editora ABPMC/ARBytes, 1997. 